\title{
Dampak Kebijakan Billing System Penebusan Pupuk Subsidi di Provinsi Lampung
}

\author{
The Impact of Billing System Policy for Subsidized Fertilizer Redemption \\ in Lampung Province
}

\author{
Muhammad Ibnu
}

\author{
Jurusan Agribisnis Fakultas Pertanian Universitas Lampung \\ Jl. Prof. Dr. Soemantri Brojonegoro No. 1 Bandar Lampung 35145 \\ Email/HP: ibnulpg@yahoo.com; muhammad.ibnu@fp.unila.ac.id /081283825136
}

\begin{abstract}
S
To address the problems of the distribution of subsidized fertilizers, the Government of Lampung Province implements an innovative Billing System policy through which farmer groups redeem subsidized fertilizer online. However, the impact of the policy has not been reviewed scientifically. Therefore, this study aims to answer questions (1) what are the impacts of the Billing System Policy on the quantity use and prices of subsidized fertilizer in Lampung? and (2) what are the impacts of the Billing System Policy on rice production in Lampung? The study was conducted in June 2020 until February 2021. Total respondents were 314 rice farmers surveyed with systematic random sampling in the districts of East dan South Lampung and Metro. The impacts of Billing Systems were evaluated with the Propensity Score Matching (PSM) technique, which is a credible quantitative method for correcting selection bias and other variable biases. The results showed that, at the farmer group level, the Billing System significantly increases the average use of Urea and reduces the average prices of Urea and SP36. However, the Billing System has little impact on rice production, although the production has increased after the Billing System policy. The findings further imply that enhancing the institutional capacity of farmers is still necessary.
\end{abstract}

Keywords: Billing System; impact evaluation; paddy; Propensity Score Matching; subsidized fertilizers

\begin{abstract}
Abstrak
Untuk mengatasi permasalahan distribusi pupuk subsidi, Pemerintah Provinsi Lampung menerapkan kebijakan inovatif (Billing System policy) agar kelompok tani menebus pupuk subsidi secara daring (online). Namun, dampak dari kebijakan tersebut belum dikaji secara ilmiah. Oleh karena itu, penelitian ini bertujuan untuk menjawab pertanyaan (1) Apakah dampak kebijakan Billing System terhadap kuantitas penggunaan dan harga pupuk bersubsidi di Lampung? dan (2) Apakah dampak kebijakan Billing System terhadap produksi padi di Lampung? Penelitian dilakukan pada bulan Juni 2020 sampai Februari 2021. Jumlah responden adalah 314 petani padi yang disurvei secara acak sistematis di Kabupaten Lampung Timur, Kabupaten Lampung Selatan, dan Metro. Evaluasi dampak dilakukan dengan teknik Propensity Score Matching (PSM) yang merupakan metode kuantitatif yang kredibel untuk mengoreksi bias seleksi dan bias variabel lainnya. Hasil penelitian menunjukkan bahwa Billing System secara signifikan meningkatkan penggunaan rata-rata Urea, dan menurunkan harga rata-rata Urea dan SP36 di tingkat kelompok tani. Namun, Billing System belum berdampak signifikan terhadap produksi padi meskipun produksi meningkat setelah kebijakan Billing System. Temuan lebih lanjut menyiratkan bahwa peningkatan kapasitas kelembagaan petani masih diperlukan.
\end{abstract}

Kata kunci: billing system; evaluasi dampak; padi; propensity score matching; pupuk subsidi 


\section{Pendahuluan}

Billing System Penebusan Pupuk dapat dianggap sebagai kebijakan dan/atau terobosan baru dalam sistem distribusi pupuk subsidi di Provinsi Lampung. Ditetapkan melalui Peraturan Gubernur Lampung nomor 99 tahun 2016 (Peraturan Gubernur Lampung, 2016), kebijakan tersebut mendorong petani (secara kolektif melalui kelompok tani) melakukan penebusan pupuk subsidi secara daring (online) sehingga diharapkan dapat menyederhanakan prosedur penebusan dan mengendalikan distribusi pupuk subsidi. Kebijakan tersebut diharapkan pula dapat menjamin ketersediaan pupuk, meningkatkan efektivitas penerapan pemupukan berimbang, meningkatkan produktivitas dan produksi komoditas pertanian, melindungi kepentingan dan meningkatkan kesejahteraan petani, serta mewujudkan pembangunan pertanian berkelanjutan (Peraturan Gubernur Lampung, 2016).

Pupuk Subsidi meliputi Pupuk Urea, Pupuk SP36, Pupuk ZA, Pupuk NPK, Pupuk Organik dan jenis pupuk subsidi lainnya yang ditetapkan oleh menteri yang menyelenggarakan urusan pemerintahan di bidang pertanian (Kementerian Pertanian, 2018a). Provinsi Lampung mendapatkan kuota pupuk subsidi tertinggi di Sumatera dan di luar pulau Jawa (Kementerian Pertanian, 2018b). Selama periode tahun 20132017, kebutuhan pupuk subsidi Provinsi Lampung berkisar antara 4,63-5,24 persen dari kebutuhan nasional, atau secara rata-rata adalah 4,9 persen dari kebutuhan nasional.

Namun, distribusi pupuk subsidi di Lampung selama periode tahun 2013-2017 belum mencapai 100 persen, yaitu berkisar antara 86,22 - 99,09 persen (lihat Gambar 1). Selama periode 2014 - 2017 terebut, rata-rata realisasi distribusi pupuk subsidi di Lampung adalah 91,48 persen dari rencana atau kuota yang dimiliki, atau lebih rendah dari rata-rata distribusi pupuk subsidi nasional yang mencapai 98,11 persen (Kementerian Pertanian, 2018b). Hal ini merefleksikan bahwa masih adanya hambatan dan/atau kendala dalam distribusi pupuk subsidi di Lampung.

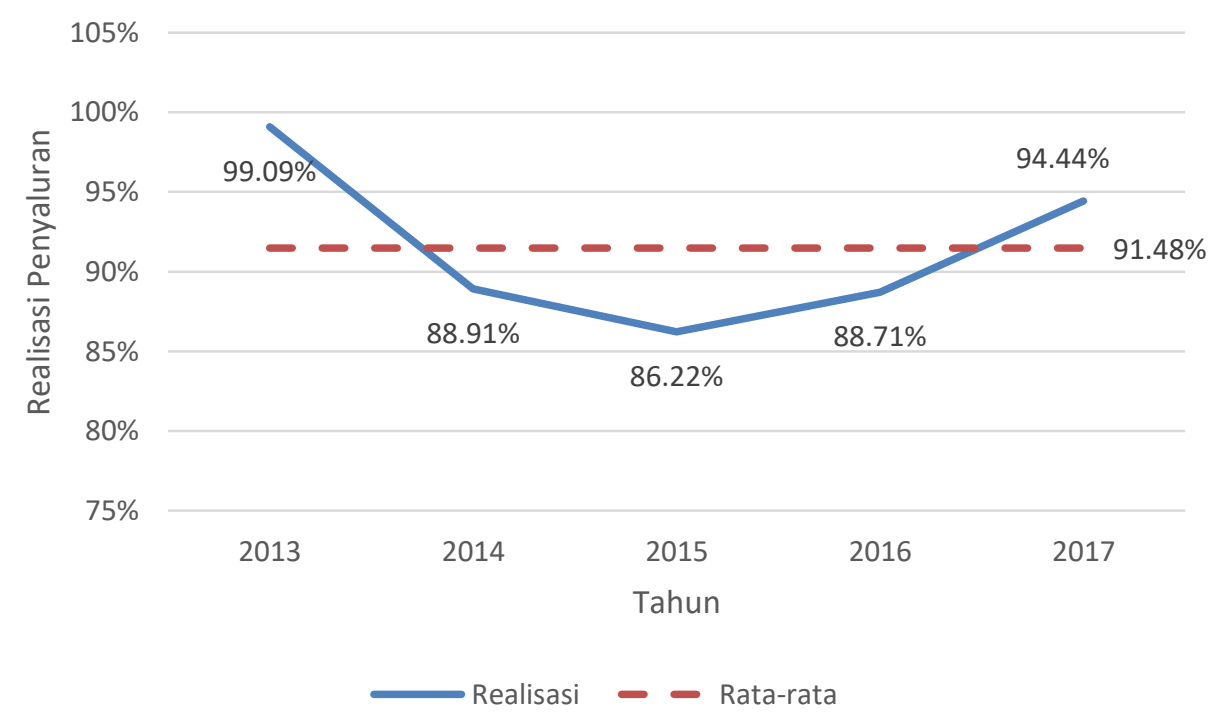

Gambar 1. Realisasi distribusi pupuk subsidi di Lampung tahun 2013-2017 Sumber: Kementerian Pertanian (2018b)

Salah satu hambatan utama dalam distribusi pupuk subsidi adalah adanya gap (perbedaan) antara perencanaan dan/atau kuota dengan realisasi distribusi (Komisi 
Pemberantasan Korupsi, 2017). Gap ini memicu timbulnya masalah turunan. Pertama, persoalan keakuratan data riil kebutuhan pupuk subsidi. Saat ini program Pupuk Subsidi dialokasikan kepada petani dengan mengacu kepada Rencana Definitif Kebutuhan Kelompok (RDKK) yang diajukan kelompok tani. Produsen pupuk juga memberikan data-data kebutuhan pupuk subsidi ke pemerintah untuk tujuan mengklaim anggaran subsidi. Namun, data RDKK dan data produsen pupuk dapat berbeda, sebab RDKK berasal dari tingkat kelompok tani sedangkan data produsen pupuk didapatkan dari konsolidasi data di tingkat kios/distributor pupuk. Kedua, manipulasi data distribusi pupuk subsidi. Hal ini rentan terjadi bila transparansi, panduan, dan kontrol pihak yang berwenang lemah di tingkat kelompok tani. Ketiga, timbulnya persepsi dan/atau isu kelangkaan pupuk subsidi. Persepsi/isu kelangkaan ini dipicu oleh kesenjangan antara RDKK yang diusulkan oleh kelompok tani dengan realisasi pupuk subsidi yang diterima oleh kelompok tani (Komisi Pemberantasan Korupsi, 2017).

Kebijakan Billing System diimplementasikan untuk mengatasi masalah-masalah terkait distribusi pupuk subsidi seperti tersebut di atas. Namun, dampak Billing System di tingkat petani belum diketahui, terutama dampak yang terkait kuantitas penggunaan dan harga pupuk subsidi, dan dampak yang terkait dengan produksi tanaman pangan (terutama padi). Penelitian yang terkait pupuk subsidi telah cukup banyak dilakukan (Indriasari \& Sani, 2019; Lasindrang \& Fauzi DH, 2018; Sari \& Fahmi, 2018; Suryana et al., 2018, 2018; Susilowati, 2018; Zulaiha et al., 2018). Namun, penelitian yang menganalisis dampak Billing System penebusan pupuk subsidi masih sangat jarang dilakukan. Hanya beberapa penelitian yang ditemukan terkait Billing System, tetapi belum fokus pada kajian mengenai dampaknya (Sukmayanto et al., 2019; Zakaria et al., 2018).

Dengan demikian, penelitian ini bertujuan untuk menjawab pertanyaanpertanyaan (1) bagaimanakah dampak Kebijakan Billing System pada kuantitas penggunaan dan harga pupuk subsidi di Provinsi Lampung? dan (2) bagaimanakah dampak Kebijakan Billing System pada produksi padi di Provinsi Lampung? Evaluasi dampak dilakukan dengan teknik Propensity Score Matching (PSM) yaitu metode kuantitatif yang kredibel untuk mengoreksi bias sehingga hasil evaluasi lebih akurat.

\section{Metode Penelitian}

\section{Lokasi, waktu, dan tahapan pengumpulan data}

Penelitian ini di lakukan di Provinsi Lampung dan difokuskan pada tanaman padi. Survei dilakukan di daerah-daerah penghasil padi di provinsi tersebut, yaitu Kabupaten Lampung timur, Kabupaten Lampung Selatan, dan Kota Metro pada bulan Juni 2020 sampai dengan Februari 2021. Kabupaten Lampung Timur dan Lampung Selatan adalah daerah penghasil padi terbesar nomor dua dan tiga di Provinsi Lampung. Kabupaten Lampung Timur dan Kabupaten Lampung Selatan berturut-turut memproduksi padi (gabah kering giling) sebesar 397.807 ton dan 244.936 ton, atau sebesar 20,93 persen dan 12,88 persen dari total produksi padi di Provinsi Lampung. Kota Metro memproduksi padi sebesar 31.123 ton atau hanya berkontribusi sebesar 1,64 persen terhadap total produksi padi Provinsi Lampung (Badan Pusat Statistik, 2020). 
Di lokasi penelitian, pada umumnya kelompok-kelompok tani yang telah berpartisipasi dalam kebijakan Billing System berada suatu desa, sedangkan kelompokkelompok tani yang belum berpartisipasi berada pada desa yang berbeda. Berdasarkan pertimbangan bahwa karakteristik petani dan kelompok tani pada sebuah desa adalah mendekati homogen, maka metode sampling yang diterapkan adalah metode sampling acak sistematis (systematic random sampling) (Legan \& Vandeven, 2003).

Pelaksanaan sampling melalui 4 (empat) tahap. Tahap pertama adalah mengidentifikasi desa-desa yang mayoritas kelompok taninya telah mengikuti Billing System dan desa-desa yang mayoritas petaninya belum berpartisipasi dalam Billing System. Desa-desa tersebut dikunjungi dan diverifikasi sehingga terpilih secara total 18 desa atau pekon sebagai lokasi survei. Petani Billing System berasal dari 4 (empat) desa atau pekon di Kota Metro, 2 (dua) pekon di Lampung Selatan, dan 2 (dua) desa atau pekon di Lampung Timur. Petani non-Billing System berasal dari 4 (empat) pekon di Lampung Selatan dan 4 (empat) pekon di Lampung Timur.

Tahap kedua adalah mendapatkan nama-nama kelompok tani dari BP3K Provinsi Lampung dan dinas pemerintah terkait. Tahap ketiga adalah membuat daftar nama petani yang diperoleh berdasarkan desa atau pekon tempat tinggalnya. Namanama petani tersebut diurutkan berdasarkan abjad namanya dan diberi nomor. Tahap keempat adalah pelaksanaan survei dan petani yang menjadi responden adalah petani dengan nomor ganjil pada daftar nama tersebut. Penelitian ini fokus pada petani yang melakukan usaha budidaya padi sawah. Survei dilakukan dengan kuesioner semi terbuka dan jumlah total responden yang disurvei adalah 314 orang petani padi dengan proporsi yang seimbang antara petani Billing System dan petani non-Billing System (lihat Tabel 1).

Tabel 1

Jumlah Responden

\begin{tabular}{|c|c|c|}
\hline Tipe Responden & Lokasi Survei & $\begin{array}{c}\text { Jumlah responden } \\
\text { (orang) }\end{array}$ \\
\hline Petani Billing System & $\begin{array}{l}\text { - } 4 \text { pekon di Kota Metro } \\
\text { - } 4 \text { pekon di Kabupaten Lampung } \\
\text { Selatan } \\
\text { - } 2 \text { pekon di Kabupaten Lampung } \\
\quad \text { Timur }\end{array}$ & $\begin{array}{l}-53 \\
-\quad 52 \\
-\quad 52\end{array}$ \\
\hline Total petani Billing System & 10 pekon & 157 \\
\hline Petani non-Billing System & $\begin{array}{l}\text { - } 4 \text { pekon di Kabupaten Lampung } \\
\text { Selatan } \\
\text { - } 4 \text { pekon di Kabupaten Lampung } \\
\text { Timur }\end{array}$ & $\begin{array}{ll}- & 78 \\
\text { - } & 79\end{array}$ \\
\hline $\begin{array}{l}\text { Total petani non-Billing } \\
\text { System }\end{array}$ & 8 pekon & 157 \\
\hline Total responden & 18 pekon & 314 \\
\hline
\end{tabular}

\section{Metode Analisis data}

Evaluasi dampak bertujuan untuk menjawab pertanyaan: bagaimana hasil (misalnya produksi padi) telah berubah jika intervensi belum/tidak dilakukan? Pertanyaan ini mencakup analisis kontra faktual, yang merupakan perbandingan antara apa yang sebenarnya terjadi (fakta) dan apa yang akan terjadi jika tidak ada 
intervensi (White, 2006). Dengan demikian, evaluasi dampak didefinisikan sebagai kesenjangan antara hasil aktual dan hasil kontra faktual (counterfactual) (Blackman \& Rivera, 2011; Ruben \& Fort, 2012; Ruben \& Zuniga, 2011; White, 2006).

Prinsip evaluasi kontra faktual bertujuan meminimalkan bias, dan bias yang sering muncul dalam evaluasi dampak adalah bias variabel-variabel lain (other variables biases) (Blackman \& Rivera, 2011; Ferraro, 2009; Frondel \& Schmidt, 2005; Khandker et al., 2009). Bias variabel-variabel lain adalah bias yang terjadi karena adanya variabelvariabel lainnya (selain Billing System) yang mempengaruhi kelompok yang diintervensi (petani Billing System) (Blackman \& Rivera, 2011; Frondel \& Schmidt, 2005; Khandker et al., 2009). Misalnya, dampak Billing System diukur sebagai perbandingan rata-rata produksi padi petani 'sebelum' (before) dan 'sesudah' (after) Billing System. Jika produksi padi sesudah Billing System ditemukan lebih tinggi daripada sebelum Billing System, maka peneliti menyimpulkan bahwa Billing System meningkatkan rata-rata produksi padi petani. Namun permasalahannya adalah, selain Billing System, terdapat variabel-variabel lain yang mungkin terlibat atau justru lebih mempengaruhi kenaikan produksi padi. Variabel-variabel lain tersebut mungkin termasuk peningkatan peran organisasi, kondisi iklim, dan kondisi air irigasi. Variabel-variabel tersebut bersaing dengan Billing System dalam hal memberikan dampak bagi produksi padi petani. Dengan demikian, besar kemungkinannya bahwa bias (variabel-variabel lain) telah terjadi dan mempengaruhi akurasi kesimpulan penelitian (Blackman \& Rivera, 2011; Frondel \& Schmidt, 2005).

Kontra faktual tidak dapat diamati secara langsung, sehingga tantangan dari evaluasi dampak adalah membentuk kelompok perbandingan yang 'ideal' dan 'sebanding' (equally matched) untuk kelompok responden yang berbeda (Blackman \& Rivera, 2011; Khandker et al., 2009; Ruben \& Fort, 2012; Ruben \& Zuniga, 2011; White, 2006). Untuk itu menjawab tantangan tersebut, penelitian ini menggunakan desain kuasi-eksperimental.

Di dalam pendekatan kuasi-eksperimental, pihak yang bebas dari intervensi (yaitu petani non-Billing System sebagai kontrol) harus benar-benar sebanding/seimbang (equally match) dengan pihak yang mendapatkan intervensi (yaitu petani Billing System) (Greenstone \& Gayer, 2009; White, 2006). Perbandingan seperti ini memberikan keseimbangan untuk semua faktor/variabel yang dapat diukur seperti layaknya eksperimen yang ideal, misalnya eksperimen di laboratorium (Frondel \& Schmidt, 2005). Dengan demikian, dalam kasus penelitian ini, petani Billing System dibandingkan dengan petani non-Billing System. Petani non-Billing System berfungsi sebagai kelompok kontrol di mana hasil/outcome (yaitu produksi padi, penggunaan dan harga pupuk subsidi) dari kelompok ini berfungsi sebagai kontra faktual. Sampel neraca dari kedua kelompok (Billing System dan non-Billing System) diambil secara proporsional dengan jumlah yang representatif agar dampak bersih Billing System pada petani dapat dievaluasi (Ruben \& Fort, 2012; Ruben \& Zuniga, 2011).

Sebagaimana yang telah disebutkan, evaluasi dampak pada penelitian ini difokuskan pada dampak Billing System pada kuantitas penggunaan dan harga pupuk subsidi, dan pada produksi padi. Data yang digunakan adalah yang berasal dari petani responden untuk 3 (tiga) tahun terakhir, yaitu 2018-2020. Selain Billing System, variabelvariabel lain yang diduga berpengaruh terhadap evaluasi dampak turut pula dimasukkan dalam analisis. Variabel-variabel tersebut berjumlah 20 meliputi umur responden, pengalaman usaha tani responden, pendidikan responden, jumlah 
tanggungan keluarga, luas lahan, rata-rata harga panen, rata-rata penggunaan pupuk subsidi (Urea, SP36, ZA, dan NPK), rata-rata harga pupuk subsidi (Urea, SP36, ZA, dan NPK), frekuensi kelompok tani bertemu penyuluh, kondisi iklim, lokasi pembelian pupuk, jarak pembelian pupuk, kondisi air irigasi, dan keaktifan kelompok tani. Daftar variabel-variabel yang digunakan dalam analisis dapat dilihat pada Tabel 2.

Tabel 2

Variabel-variabel yang digunakan di dalam analisis

\begin{tabular}{ll}
\hline Variabel & Keterangan \\
\hline Y1 & Rata-rata hasil produksi padi selama 3 (tiga) tahun terakhir $(\mathrm{kg})$ \\
BS & Partisipasi dalam Billing System (1=ya; 0=tidak) \\
X1 & Umur responden (tahun) \\
X2 & Pengalaman usaha tani responden (tahun) \\
X3 & Pendidikan responden (tahun) \\
X4 & Jumlah tanggungan keluarga (orang) \\
X5 & Luas lahan (ha) \\
X6 & Rata-rata harga jual padi selama 3 (tiga) tahun terakhir (Rp/kg) \\
X7 & Rata-rata penggunaan pupuk Urea (Kg)** \\
X8 & Rata-rata penggunaan pupuk SP36 (Kg) \\
X9 & Rata-rata penggunaan pupuk ZA (Kg) \\
X10 & Rata-rata penggunaan pupuk NPK (Kg) \\
X11 & Rata-rata harga pupuk Urea (Rp/Kg) \\
X12 & Rata-rata harga pupuk SP36 (Rp/Kg) \\
X13 & Rata-rata harga pupuk ZA (Rp/Kg) \\
X14 & Rata-rata harga pupuk NPK (Rp/Kg) \\
X15 & Frekuensi bertemu Penyuluh (per musim tanam) \\
X16 & Kondisi iklim (1=baik/mendukung; 0=tidak baik) \\
X17 & Lokasi pembelian Pupuk (1= kelompok tani, 0= lainnya/kios/agen) \\
X18 & Jarak pembelian pupuk (Km) \\
X19 & Kondisi air irigasi (1=baik/mendukung; 0=tidak baik) \\
X20 & Keaktifan kelompok Tani (2=aktif; $1=$ kurang aktif; 0=tidak aktif) \\
\hline ** di lokasi penelitian, petani hanya menggunakan pupuk subsidi Urea, SP36, ZA, dan \\
NPK &
\end{tabular}

Asumsi dasar dari penelitian ini adalah, apabila kedua kelompok responden (petani Billing System dan petani non-Billing System) benar-benar sebanding/seimbang dalam hal 20 variabel di atas, maka dampak 'bersih' Billing System dapat diukur secara meyakinkan (meminimalkan bias). Dengan kata lain, perbedaan pendapatan antara kedua kelompok responden adalah murni dampak Billing System apabila karakteristik kedua kelompok tersebut benar-benar sebanding/seimbang dalam hal umur, pengalaman usaha tani, pendidikan, jumlah tanggungan keluarga, luas lahan, rata-rata harga panen dan lain-lain.

Selanjutnya, data yang diperoleh dianalisis dengan metode Propensity Score Matching (PSM) sebagai salah satu metodologi kuantitatif dalam desain kuasieksperimental. PSM bertujuan mengevaluasi dampak dengan kemampuan mengoreksi bias sehingga temuan lebih akurat (Ruben \& Fort, 2012; Ruben \& Zuniga, 2011). Teknik PSM yang digunakan adalah Nearest Neighbour Matching yang meminimalkan bias dengan cara meminimalkan perbedaan mutlak skor kecenderungan yang diperkirakan 
(estimated propensity score) antara kelompok yang mendapatkan intervensi (petani Billing System) dan kelompok kontrol (petani non-Billing System). Penelitian ini menggunakan software Statistics/Data Analysis (Stata versi 15) untuk melakukan perhitungan teknik PSM.

\section{Hasil dan Pembahasan}

\section{Karakteristik Usaha Tani Padi di Lokasi Penelitian}

Berdasarkan wawancara, hampir seluruh petani responden membudidayakan tanaman padi untuk dijual, baik sebagian atau seluruhnya. Sebagian besar petani menjual hasil panennya kepada pedagang pengumpul (71,60 persen) dan penggilingan padi (20,82 persen). Sebagian besar petani responden menyatakan bahwa mereka membudidayakan padi inbrida jenis unggul dengan varietas Ciherang dan/atau IR-64, walaupun ada pula petani yang membudidayakan padi hibrida.

Petani menyatakan bahwa terdapat sejumlah kendala dalam usaha budidaya padi. Kendala-kendala yang dominan adalah kesulitan pembiayaan usaha, kenaikan ongkos produksi, serangan hama, perubahan iklim dan atau bencana alam (seperti banjir), kesulitan dalam mendapatkan dan mengupah pekerja, serta kehilangan (susut) hasil panen. Namun, Mayoritas petani menyatakan bahwa jenis bantuan yang paling dibutuhkan untuk budidaya tanaman padi adalah bantuan pupuk.

Tampaknya tingkat ketergantungan petani terhadap pupuk kimia/anorganik masih sangat tinggi. Hal ini terlihat dari tidak adanya responden yang menyatakan bahwa mereka mengandalkan pupuk organik (seperti pupuk kandang dan pupuk kompos) sebagai pengganti pupuk kimia untuk budidaya padi sawah.

Sebagian besar petani (lebih dari 80 persen) menjadi anggota kelompok tani, dan sisanya tidak menjadi anggota. Lokasi kelompok tani yang jauh atau belum ada kelompok tani di wilayah tempat tinggal mereka merupakan alasan utama dari petani yang tidak menjadi anggota kelompok tani.

Walaupun petani menyatakan keterbatasan modal adalah salah satu kendala usaha tani padi, petani tampaknya tidak antusias meminjam pada bank. Hanya sebagian kecil yang menyatakan mendapatkan pinjaman dari bank. Menurut petani, alasan utama enggan meminjam dari bank adalah prosedur peminjaman yang dirasa sulit, tidak mempunyai agunan, dan lokasi bank yang cukup jauh dari tempat tinggalnya. Untuk mengatasi keterbatasan modal usaha, mayoritas petani responden (90 persen) memperoleh pinjaman dengan bunga dari perorangan untuk pembiayaan kegiatan usaha taninya.

\section{Karakteristik Responden}

Tabel 3 menampilkan karakteristik rata-rata responden yang disurvei. Dari tabel tersebut dapat dilihat bahwa rata-rata produksi padi (gabah kering giling/GKG) selama 3 (tiga) tahun terakhir adalah 6.310,51 kilogram dengan rata-rata luas lahan sebesar 0,97 hektar. Pada umumnya usia responden adalah 52,09 tahun dengan pengalaman usaha tani padi selama 28,00 tahun. Responden sebagian besar tidak memiliki pendidikan formal yang tinggi, yaitu rata-rata hanya 10,02 tahun atau tidak menamatkan sekolah menengah atas atau yang sederajat. Dari Tabel 3 tersebut dapat 
dilihat pula bahwa tidak ada responden yang menggunakan pupuk organik subsidi dalam budidaya padinya.

Tabel 3

Karakteristik Responden

\begin{tabular}{|c|c|c|c|c|}
\hline & Variabel & Observasi & $\begin{array}{l}\text { Rata- } \\
\text { rata/ } \\
\text { means }\end{array}$ & $\begin{array}{r}\text { Simpangan } \\
\text { baku/ } \\
\text { standar } \\
\text { deviasi }\end{array}$ \\
\hline $\mathrm{Y}$ & $\begin{array}{l}\text { Rata2 hasil produksi padi GKG selama } 3 \text { (tiga) tahun terakhir } \\
(\mathrm{kg})\end{array}$ & 314 & $6.310,51$ & $3.222,81$ \\
\hline $\mathrm{X} 1$ & Umur responden (tahun) & 314 & 52,09 & 7,26 \\
\hline $\mathrm{X} 2$ & Pengalaman usaha tani responden (tahun) & 314 & 28,00 & 3,77 \\
\hline X3 & Pendidikan responden (tahun) & 314 & 10,02 & 2,57 \\
\hline $\mathrm{X} 4$ & Jumlah tanggungan keluarga (orang) & 314 & 5,64 & 1,63 \\
\hline X5 & Luas lahan (ha) & 314 & 0,97 & 0,40 \\
\hline X6 & $\begin{array}{l}\text { Rata2 harga jual hasil panen selama } 3 \text { (tiga) tahun terakhir } \\
(\mathrm{Rp} / \mathrm{kg})\end{array}$ & 314 & $4.312,10$ & 327,42 \\
\hline $\mathrm{X} 7$ & Rata-rata penggunaan pupuk Urea $(\mathrm{Kg})$ & 314 & 119,60 & 48,53 \\
\hline $\mathrm{X} 8$ & Rata-rata penggunaan pupuk SP36 (Kg) & 314 & 54,13 & 21,31 \\
\hline X9 & Rata-rata penggunaan pupuk ZA (Kg) & 314 & 2,64 & 1,16 \\
\hline $\mathrm{X} 10$ & Rata-rata penggunaan pupuk NPK (Kg) & 314 & 73,47 & 28,95 \\
\hline $\mathrm{X} 11$ & Rata-rata harga pupuk Urea $(\mathrm{Rp} / \mathrm{Kg})$ & 314 & $2.287,26$ & 213,96 \\
\hline $\mathrm{X} 12$ & Rata-rata harga pupuk SP36 (Rp/Kg) & 314 & $2.250,32$ & 119,17 \\
\hline $\mathrm{X} 13$ & Rata-rata harga pupuk ZA (Rp/Kg) & 314 & $1.630,89$ & 114,60 \\
\hline X14 & Rata-rata harga pupuk NPK (Rp/Kg) & 314 & $2.646,82$ & 113,92 \\
\hline X15 & Frekuensi bertemu Penyuluh (per musim tanam) & 314 & 5,94 & 1,42 \\
\hline X16 & Kondisi iklim ( $1=$ baik/mendukung; $0=$ tidak baik) & 314 & 0,51 & 0,50 \\
\hline $\mathrm{X} 17$ & Lokasi pembelian Pupuk ( $1=$ kelompok tani, $0=$ lainnya $)$ & 314 & 0,55 & 0,50 \\
\hline $\mathrm{X} 18$ & Jarak pembelian pupuk (Km) & 314 & 3,10 & 1,43 \\
\hline X19 & Kondisi air irigasi ( $1=$ baik / mendukung; $0=$ tidak baik) & 314 & 0,50 & 0,50 \\
\hline $\mathrm{X} 20$ & $\begin{array}{l}\text { Keaktifan kelompok Tani (2=aktif; } 1=\text { kurang aktif; } 0=\text { tidak } \\
\text { aktif) }\end{array}$ & 314 & 1,55 & 0,50 \\
\hline
\end{tabular}

Terkait pupuk subsidi, mayoritas petani membelinya secara kolektif melalui kelompok tani dan rata-rata membayar lebih mahal dibandingkan Harga Eceran Tertinggi (HET) pupuk subsidi yang ditetapkan pemerintah (lihat Tabel 4). Penyebab utamanya adalah karena adanya biaya transportasi yang dibebankan oleh kelompok tani pada HET pemerintah.

Tabel 4

HET Pemerintah dan HET ditingkat kelompok tani

\begin{tabular}{lccc}
\hline Jenis Pupuk Subsidi & $\begin{array}{c}\text { Harga HET Pemerintah } \\
(\mathrm{Rp} / \mathrm{kg})^{*}\end{array}$ & $\begin{array}{c}\text { Rata-rata harga HET } \\
\text { di kelompok tani }(\mathrm{Rp} / \mathrm{kg})\end{array}$ & $\begin{array}{c}\text { Selisih } \\
(\mathrm{Rp} / \mathrm{kg})\end{array}$ \\
\hline Pupuk Urea & 1800 & $2.287,26$ & 487,26 \\
Pupuk SP-36 & 2000 & $2.250,32$ & 250,32 \\
Pupuk ZA & 1400 & $1.630,89$ & 230,89 \\
Pupuk NPK & 2300 & $2.646,82$ & 346,82 \\
\hline
\end{tabular}

* Berdasarkan Peraturan Menteri Pertanian Nomor 47/permentan/SR.310/11/2018 (Kementerian

Pertanian, 2018a) 


\section{Dampak Billing System pada kuantitas penggunaan dan harga pupuk Urea, NPK, ZA dan SP36}

Langkah pertama Analisis Propensity Score Matching (PSM) adalah standarisasi perbedaan rata-rata (means) dan varians (variances) kedua group responden. Tujuan standarisasi adalah untuk menghilangkan bias yang ada dalam rangka membentuk perbandingan yang ideal/seimbang (equally match) antara kedua grup responden. Standarisasi means pada prinsipnya adalah mengoreksi perbedaan rata-rata keseluruhan akibat perbedaan rata-rata antar kelompok yang dibandingkan (misanya karena adanya data pencilan atau outlier). Varians (variances) adalah ukuran variabilitas data yang menunjukkan besaran fluktuasi data. Dengan demikian, standarisasi varians adalah mengoreksi fluktuasi data keseluruhan karena adanya fluktuasi data pada dua kelompok yang diperbandingkan (Mead, 2017; Stata Corp, 2018).

Setelah means dan variances dari data primer (rawa data) di standarisasi, maka perbandingan ideal (equally match) antara kedua grup responden telah terbentuk (lihat Gambar 2). Perbandingan yang equally match antara dua kelompok responden ini akan menghasilkan evaluasi dampak Billing System yang lebih akurat.

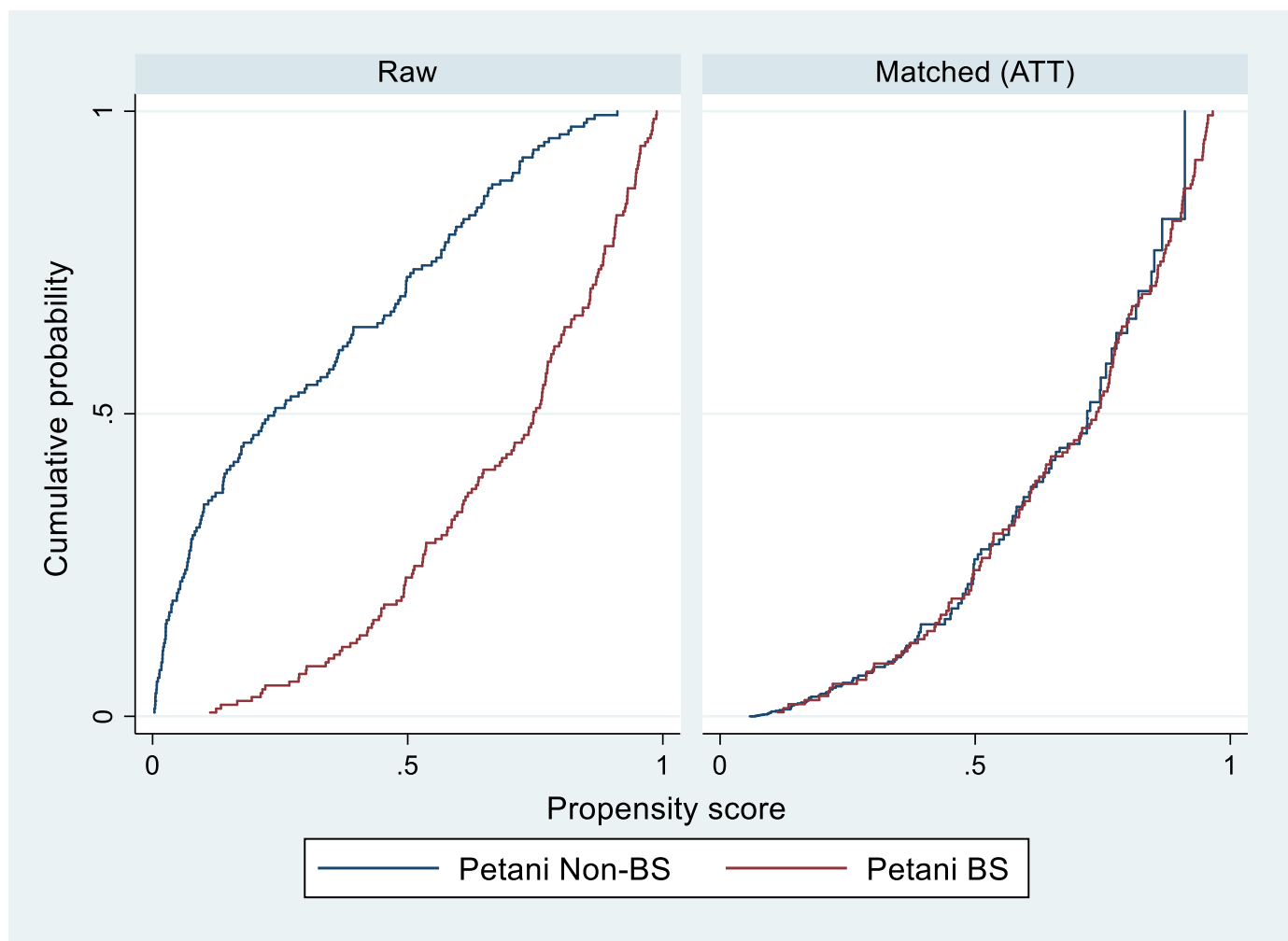

Gambar 2. Perbandingan data sebelum dan sesudah dilakukan standarisasi dan diseimbangkan (matched)

Setelah bias dikoreksi, PSM menampilkan output perhitungan dampak rata-rata Billing System terhadap penggunaan dan harga pupuk (lihat Tabel 5 ). Dari tabel tersebut dapat dilihat bahwa Billing System memiliki dampak rata-rata (Average treatment effect among treated/ATT) yang signifikan (koefisien t-test $>2$ ) pada harga pupuk Urea dan harga pupuk SP36. ATT memiliki tanda yang negatif $(-111,47$ dan $58,60)$ dan hal ini berarti bahwa Billing System telah berdampak menurunkan harga rata-rata pupuk Urea dan SP36 di tingkat petani sebesar masing-masing 111,47 
rupiah/kg dan 58,60 rupiah/kg. Dengan menurunnya harga Urea ditingkat petani, maka kuantitas penggunaan Urea meningkat secara signifikan sebesar rata-rata 20,58 kilogram. Penggunaan pupuk SP36 juga meningkat sebesar 1,76 kilogram namun tidak signifikan secara statistik.

Pada tabel 5 dapat dilihat pula bahwa Billing System tidak memiliki dampak yang signifikan (koefisien t-test $<2$ ) pada harga pupuk ZA dan NPK. Penggunaan pupuk NPK tidak berubah secara signifikan (koefisien $\mathrm{t}$-test $<2$ ), tetapi penggunaan pupuk ZA justru turun secara signifikan (koefisien t-test $>2$ ) sebesar 0,82 kilogram. Hal ini menunjukkan bahwa petani cukup sensitif terhadap perubahan harga. Tampaknya petani cenderung mengurangi penggunaan ZA dan mengalihkan pembeliannya untuk Urea karena turunnya harga HET Urea yang signifikan ditingkat Kelompok Tani.

Tabel 5

Dampak Billing System pada kuantitas penggunaan dan harga pupuk Urea, NPK, ZA dan SP36

\begin{tabular}{|c|c|c|c|c|c|}
\hline $\begin{array}{c}\text { Dampak yang Billing System yang } \\
\text { dievaluasi }\end{array}$ & $\begin{array}{c}\text { Kelompok } \\
\text { yang } \\
\text { diintervensi/ } \\
\text { treated group } \\
*\end{array}$ & $\begin{array}{c}\text { Kelompok } \\
\text { kontrol/ } \\
\text { untreated } \\
\text { group }^{* *}\end{array}$ & $\begin{array}{c}\text { Dampak } \\
\text { rata-rata/ } \\
\text { Average } \\
\text { treatment } \\
\text { effect among } \\
\text { treated } \\
\text { (ATT)*** }\end{array}$ & $\begin{array}{l}\text { Standar } \\
\text { galat/ } \\
\text { standard } \\
\text { error }\end{array}$ & $\begin{array}{l}\text { Nilai uji t/ } t- \\
\text { test }\end{array}$ \\
\hline Rata-rata penggunaan pupuk Urea (Kg) & 157 & 62 & 20,58 & 5,15 & $3,99 * * * *$ \\
\hline Rata-rata penggunaan pupuk SP36 (Kg) & 157 & 59 & 1,76 & 3,46 & 0,51 \\
\hline Rata-rata penggunaan pupuk ZA (Kg) & 157 & 58 & $-0,82$ & 0,17 & $-4,98 * * *$ \\
\hline Rata-rata penggunaan pupuk NPK (Kg) & 157 & 57 & $-3,17$ & 6,18 & $-0,51$ \\
\hline Rata-rata harga pupuk Urea $(\mathrm{Rp} / \mathrm{Kg})$ & 157 & 59 & $-111,47$ & 18,74 & $-5,95^{* * * *}$ \\
\hline Rata-rata harga pupuk SP36 (Rp/Kg) & 157 & 63 & $-58,60$ & 17,73 & $-3,31^{* * * *}$ \\
\hline Rata-rata harga pupuk $\mathrm{ZA}(\mathrm{Rp} / \mathrm{Kg})$ & 157 & 57 & $-49,05$ & 41,66 & $-1,18$ \\
\hline Rata-rata harga pupuk NPK (Rp/Kg) & 157 & 54 & $-38,85$ & 22,04 & $-1,76$ \\
\hline
\end{tabular}

* Jumlah petani Billing System yang digunakan dalam analisis PSM

** Jumlah Petani non-Billing System yang karakteristiknya seimbang/equally match dengan petani Billing System

*** ATT (Average treatment effect among treated), yaitu dampak rata-rata Billing System pada harga dan kuantitas penggunaan pupuk

**** Signifikan pada selang (interval) kepercayaan $95 \%$ (95\% level of confidence)

Selanjutnya Tabel 6 menunjukkan rata-rata bias yang telah dikoreksi oleh teknik PSM untuk penggunaan dan harga pupuk. Tabel tersebut menunjukkan rata-rata bias dan interval bias yang telah dikoreksi. Misalnya rata-rata harga pupuk Urea $(\mathrm{kg})$ memiliki bias yang telah dikoreksi berkisar antara -421.31 sampai dengan -173.68 dengan rata-rata bias yang telah dikoreksi sebesar 5,52. Tanda negatif menunjukkan bahwa, apabila bias tidak dikoreksi, bias akan meningkat secara negatif yang berarti rata-rata harga pupuk seolah-olah menjadi lebih rendah. 
Tabel 6

Bias yang telah dikoreksi oleh PSM

\begin{tabular}{|c|c|c|c|c|c|}
\hline \multirow{2}{*}{$\begin{array}{l}\text { Variabel/variable } \\
\text { Rata-rata penggunaan pupuk Urea }(\mathrm{Kg})\end{array}$} & \multirow{2}{*}{\begin{tabular}{|l|} 
Bias \\
5,52
\end{tabular}} & \multirow{2}{*}{$\begin{array}{r}\text { Standar } \\
\text { galat/ } \\
\text { standard } \\
\text { error } \\
5,15\end{array}$} & \multicolumn{3}{|c|}{$\begin{array}{l}\text { Selang kepercayaan } 95 \% / \\
95 \% \text { level of confidence }\end{array}$} \\
\hline & & & 6,27 & 34,89 & $(N)^{*}$ \\
\hline & & & 19,63 & 32,68 & $(\mathrm{P})^{* *}$ \\
\hline & & & 19,63 & 28,99 & $(\mathrm{BC})^{* * *}$ \\
\hline \multirow[t]{3}{*}{ Rata-rata penggunaan pupuk SP36 (Kg) } & 0,05 & 3,46 & $-7,85$ & 11,36 & $(\mathrm{~N})$ \\
\hline & & & $-3,36$ & 4,86 & $(\mathrm{P})$ \\
\hline & & & $-3,36$ & 4,86 & (BC) \\
\hline \multirow[t]{3}{*}{ Rata-rata penggunaan pupuk ZA (Kg) } & 0,04 & 0,17 & $-1,28$ & $-0,36$ & $(\mathrm{~N})$ \\
\hline & & & $-0,99$ & $-0,55$ & $(\mathrm{P})$ \\
\hline & & & $-0,99$ & $-0,55$ & (BC) \\
\hline \multirow{3}{*}{ Rata-rata penggunaan pupuk NPK (Kg) } & 0,31 & 6,18 & $-20,33$ & 14,00 & $(\mathrm{~N})$ \\
\hline & & & $-10,40$ & 3,92 & $(\mathrm{P})$ \\
\hline & & & $-10,40$ & 3,92 & (BC) \\
\hline \multirow[t]{3}{*}{ Rata-rata harga pupuk Urea $(\mathrm{Rp} / \mathrm{Kg})$} & 1,52 & 18,74 & $-163,50$ & $-59,43$ & $(\mathrm{~N})$ \\
\hline & & & $-135,26$ & $-86,25$ & $(\mathrm{P})$ \\
\hline & & & $-135,26$ & $-86,25$ & (BC) \\
\hline \multirow[t]{3}{*}{ Rata-rata harga pupuk SP36 (Rp/Kg) } & 9,65 & 17,73 & $-107,83$ & $-9,36$ & $(\mathrm{~N})$ \\
\hline & & & $-71,25$ & $-31,33$ & (P) \\
\hline & & & $-71,25$ & $-31,33$ & (BC) \\
\hline \multirow[t]{3}{*}{ Rata-rata harga pupuk ZA (Rp/Kg) } & 21,50 & 41,66 & $-164,72$ & 66,63 & $(\mathrm{~N})$ \\
\hline & & & $-76,73$ & 24,83 & $(\mathrm{P})$ \\
\hline & & & $-76,73$ & 24,83 & (BC) \\
\hline \multirow[t]{3}{*}{ Rata-rata harga pupuk NPK (Rp/Kg) } & 5,76 & 22,04 & $-100,04$ & 22,33 & $(\mathrm{~N})$ \\
\hline & $-3,45$ & & $-63,06$ & $-3,45$ & $(\mathrm{P})$ \\
\hline & $-3,45$ & & $-63,06$ & $-3,45$ & (BC) \\
\hline
\end{tabular}

* distribusi normal/ normal distribution

** persentil/percentile

*** bias dikoreksi/ bias-corrected

\section{Dampak Billing System pada produksi padi}

Tabel 7 menunjukkan hasil analisis PSM untuk dampak Billing System pada ratarata produksi padi. Dapat dilihat pada tabel tersebut bahwa ATT (Average treatment effect among treated) untuk produksi padi adalah positif $(353,503)$. Hal ini berarti, implementasi Billing System telah berdampak dalam hal menaikkan produksi rata-rata padi sebesar 353,503 kilogram. Namun, dampak Billing System pada produksi tersebut belum dapat dikategorikan signifikan secara statistik (koefisien t-test $<2$ ).

Tabel 7

Dampak Billing System pada produksi padi petani

\begin{tabular}{rrrrr}
\hline $\begin{array}{c}\text { Kelompok yang } \\
\text { diintervensi/ treated } \\
\text { group }^{*}\end{array}$ & $\begin{array}{c}\text { Kelompok kontrol/ } \\
\text { untreated group }\end{array}$ & $\begin{array}{c}\text { Dampak rata-rata/ } \\
\text { Average treatment } \\
\text { effect among treated } \\
\text { (ATT) }{ }^{* * *}\end{array}$ & $\begin{array}{c}\text { Standar galat/ } \\
\text { standard error }\end{array}$ & $\begin{array}{c}\text { Nilai uji t/ } t \text { - } \\
\text { test }\end{array}$ \\
\hline 157 & 55 & 353,503 & $1.329,827$ & $0,266^{* * * *}$
\end{tabular}

* Jumlah petani Billing System yang digunakan dalam analisis PSM

** Jumlah Petani non-Billing System yang karakteristiknya seimbang/equally match dengan petani Billing System

*** ATT (Average treatment effect among treated), yaitu dampak rata-rata Billing System pada produksi padi

**** Dampak tidak signifikan pada selang (interval) kepercayaan 95 \% (95\% level of confidence)

Selanjutnya Tabel 8 menunjukkan rata-rata bias yang telah dikoreksi untuk dampak Billing sistem pada produksi padi. Bias yang dikoreksi berkisar antara 2.765,63 
sampai dengan 2.765.63 dengan rata-rata bias yang dikoreksi sebesar 727,18. Bias memiliki nilai yang positif sehingga, apabila bias tidak dikoreksi, maka bias akan meningkat dengan arah yang positif pula.

Tabel 8

Bias yang telah dikoreksi oleh PSM

\begin{tabular}{lccccc}
\hline \multirow{2}{*}{ Variabel/variable } & \multirow{2}{*}{ Bias } & $\begin{array}{c}\text { Standar galat/ } \\
\text { standard error }\end{array}$ & \multicolumn{2}{c}{$\begin{array}{c}\text { Selang kepercayaan 95\%/ } \\
\text { 95\% level of confidence }\end{array}$} \\
\hline Produksi (kg) & 727,18 & $1.329,83$ & $-3.338,69$ & $4.045,70$ & $(\mathrm{~N})^{*}$ \\
& & $-264,33$ & $2.765,63$ & 2.765 .63 & $(\mathrm{P})^{* *}$ \\
& & $-264,33$ & $2.765,63$ & 2.765 .63 & $(\mathrm{BC})^{* * *}$ \\
\hline
\end{tabular}

* distribusi normal/ normal distribution

** persentil/percentile

*** bias dikoreksi/ bias-corrected

Temuan di atas menunjukkan bahwa Billing System memiliki dampak signifikan yang belum optimal. Hal ini terkait dengan penerapan sistem tersebut yang masih memiliki beberapa kendala. Di tingkat petani, kendala utama adalah banyaknya kelompok tani yang belum memiliki organisasi yang kuat. Bahkan, untuk petani nonBilling System, absennya kelompok tani yang dapat diandalkan untuk menaungi mereka merupakan penyebab utama mereka belum berpartisipasi dalam sistem distribusi pupuk online tersebut.

Bagi kelompok tani, kesulitan dalam hal administrasi dan modal masih menjadi persoalan penting yang perlu diatasi. Kendala administrasi pada umumnya terkait dengan kesulitan kelompok tani untuk mendisiplinkan anggotanya agar dapat menyetorkan biaya pembelian pupuk dengan tepat waktu. Beberapa kelompok tani menyatakan bahwa kerumitan ini terjadi karena, selain karakter individual petani yang sulit dibina, beberapa anggota kelompok berdomisili di lain desa, hanya lahannya saja yang berada di wilayah kerja kelompok tani yang bersangkutan. Kendala administrasi ini berpengaruh pada modal yang dimiliki oleh kelompok tani sehingga hak atau jatah pupuk subsidi kelompok tani (berdasarkan Rencana Definitif Kebutuhan Kelompok/RDKK) terlambat ditebus atau bahkan tidak seluruhnya dapat ditebus. Hal ini selanjutnya berdampak pada kuantitas penggunaan pupuk dan hasil produksi padi yang belum optimal.

Namun demikian, berdasarkan wawancara, pada umumnya baik petani Billing System maupun non-Billing System menyambut positif kebijakan sistem distribusi pupuk online tersebut. Menurut petani, Billing System memiliki potensi mendukung prinsip distribusi pupuk subsidi '6 tepat' (tepat waktu, tepat harga, tepat jenis, tepat jumlah, tepat mutu, dan tepat tempat). Namun, kendala-kendala di tingkat kelompok tani terutama dalam hal administrasi dan permodalan. harus diatasi.

Wawancara dan observasi juga menunjukkan bahwa Billing System merupakan suatu terobosan yang penting dalam hal sistem distribusi pupuk subsidi. Pertama, Billing System berpotensi meningkatkan kemampuan manajerial petani. Melalui Billing System, petani memiliki kesempatan untuk meningkatkan kemampuan mengatur dan kebebasan menggunakan alokasi pupuk subsidi sesuai dengan kebutuhannya. Kedua, bagi pemerintah daerah, Billing System berpotensi menjadikan aparat pemerintah daerah lebih fokus menjalankan fungsi pembinaan kelompok tani agar produktivitas tanaman pangan semakin meningkat. Dengan adanya Billing System, sumber daya pemerintah daerah baik pegawai maupun anggaran, yang sebelumnya digunakan untuk melakukan verifikasi dan validasi data distribusi pupuk subsidi di tingkat 
kelompok tani, dapat dialokasikan untuk kegiatan pembinaan dan kegiatan-kegiatan produktif lainnya.

\section{Kesimpulan}

Hasil penelitian menunjukkan bahwa dampak Billing System ditemukan signifikan menurunkan rata-rata harga jual pupuk Urea dan SP36 di tingkat petani. Kuantitas penggunaan Urea juga meningkat secara signifikan, namun penggunaan pupuk SP36 tidak berubah secara signifikan.

Namun, Billing System tidak memiliki dampak yang signifikan pada harga pupuk ZA dan NPK. Penggunaan pupuk NPK tidak berubah secara signifikan, tetapi penggunaan pupuk ZA justru turun secara signifikan. Hal ini menunjukkan bahwa penggunaan pupuk cukup responsif terhadap perubahan harga. Petani cenderung mengurangi penggunaan ZA dan mengalihkan pembeliannya untuk Urea. Terkait produksi padi, implementasi Billing System ditemukan berdampak dalam hal menaikkan produksi rata-rata padi. Namun, kenaikan produksi tersebut belum dapat dikategorikan signifikan secara statistik.

Dengan demikian, Billing System memiliki dampak yang masih terbatas. Hal ini terkait dengan penerapan sistem tersebut yang masih memiliki beberapa kendala yang bersumber dari masih lemahnya organisasi petani. Oleh karena itu, peningkatan kapasitas kelembagaan kelompok tani, baik dari sisi sumber daya manusia maupun modal, sangat perlu diperhatikan. Berbagai pihak, termasuk penyuluh, dinas pertanian, pemerintah daerah dan institusi pendidikan (universitas) diharapkan terus berperan aktif dalam pembinaan organisasi dan/atau kelompok tani.

\section{Daftar Pustaka}

Badan Pusat Statistik. (2020). Luas panen dan produksi padi di Indonesia 2019. Jakarta: Badan Pusat Statistik.

Blackman, A., \& Rivera, J. (2011). Producer-Level Benefits of Sustainability Certification. Conservation Biology, 25(6), 1176-1185. https://doi.org/10.1111/j.15231739.2011.01774.x

Ferraro, P. J. (2009). Counterfactual thinking and impact evaluation in environmental policy. New Directions for Evaluation, 2009(122), 75-84. https://doi.org/10.1002/ev.297

Frondel, M., \& Schmidt, C. M. (2005). Evaluating environmental programs: The perspective of modern evaluation research. Ecological Economics, 55(4), 515-526. https://doi.org/10.1016/j.ecolecon.2004.12.013

Greenstone, M., \& Gayer, T. (2009). Quasi-experimental and experimental approaches to environmental economics. Journal of Environmental Economics and Management, 57(1), 21-44. https://doi.org/10.1016/j.jeem.2008.02.004

Indriasari, D. P., \& Sani, A. (2019). PENGENDALIAN MANAJEMEN PUPUK SUBSIDI. Jurnal Aplikasi Manajemen \& Kewirausahaan MASSARO, 1(1). https://doi.org/10.37476/massaro.v1i1.642 
Kementerian Pertanian. (2018a). Peraturan Menteri Pertanian Republik Indonesia Nomor47/permentan/SR.310/11/2018 tentang alokasi dan haga eceran tertinggi pupuk bersubsidi sektor pertanian tahun anggaran 2019. Jakarta: Kementerian Pertanian Republik Indonesia.

Kementerian Pertanian. (2018b). Statistik pertanian 2017. Jakarta: Kementerian Pertanian Republik Indonesia.

Khandker, S., B. Koolwal, G., \& Samad, H. (2009). Handbook on Impact Evaluation. https:/ / doi.org/10.1596/978-0-8213-8028-4

Komisi Pemberantasan Korupsi. (2017). Kajian kebijakan subsidi di bidang pertanian. Jakarta: Komisi Pemberantasan Korupsi.

Lasindrang, R. Z. Y., \& Fauzi DH, A. (2018). Hubungan distribusi terhadap penjualan (Studi Pada Distribusi Pupuk Npk Non Subsidi Area Pemasaran Kalimantan Di Pt. Pupuk Kalimantan Timur). Jurnal Administrasi Bisnis, 54(1), 197-206.

Legan, D., \& Vandeven, M. H. (2003). Sampling techniques. In Detecting Pathogens in Food. John Wiley \& Sons. https:/ / doi.org/10.1016/B978-1-85573-670-2.50007-5

Mead, R. (2017). Statistical methods in agriculture and experimental biology. Chapman and Hall/CRC. https:/ / doi.org/0.1201/9781315275772

Peraturan Gubernur Lampung. (2016). Peraturan Gubernur Lampung Nomor 99 tahun 2016 tentang pola distribusi pupuk bersubsidi di sektor pertanian di Provinsi Lampung. Provinsi Lampung: Gubernur Lampung.

Ruben, R., \& Fort, R. (2012). The Impact of Fair Trade Certification for Coffee Farmers in Peru. World Development, 40(3), 570-582. https:/ / doi.org/10.1016/j.worlddev.2011.07.030

Ruben, R., \& Zuniga, G. (2011). How standards compete: comparative impact of coffee certification schemes in Northern Nicaragua. Supply Chain Management: An International Journal, 16(2), 98-109. https:/ / doi.org/10.1108/13598541111115356

Sari, L. R., \& Fahmi, A. (2018). Dampak subsidi pupuk terhadap peningkatan pendapatan dan kesejahteraan petani kecamatan megaluh jombang dalam perspektif fenomenologis. MARGIN ECO, 2(2), 86-101.

Stata Corp. (2018). Selection Model Heckoprobit. Retrieved from http://www.stata.com/Manuals14/Svysvyestimation.Pdf.

Sukmayanto, M., Alviana, E. D., \& Muhtholib, A. (2019). Persepsi petani padi terhadap program billing sistem di kecamatan metro barat kota metro. Mimbar Agribisnis: Jurnal Pemikiran Masyarakat Ilmiah Berwawasan Agribisnis, 5(1), 114-123.

Suryana, A., Agustian, A., \& Yofa, R. D. (2018). Alternatif Kebijakan Penyaluran Subsidi Pupuk Bagi Petani Pangan. Analisis Kebijakan Pertanian, 14(1), 35. https:/ / doi.org/10.21082/akp.v14n1.2016.35-54 
Susilowati, S. H. (2018). Urgensi dan Opsi Perubahan Kebijakan Subsidi Pupuk. Analisis Kebijakan Pertanian, 14(2), 163. https:/ / doi.org/10.21082/akp.v14n2.2016.163-185

White, H. (2006). Impact evaluation: the experience of the Independent Evaluation Group of the World Bank. Independent Evaluation Group, the World Bank.

Zakaria, W. A., Ibnu, M., Marlina, L., \& Endaryanto, T. (2018). Evaluasi KinerjaKebijakan Billing Sistem Penebusan Pupuk Subsidi Dalam Rangka Mencapai Target Swasembada Pangan di Provinsi Lampung. Retrieved from http:/ / repository.lppm.unila.ac.id/10203/2/Makalah Billing System.pdf

Zulaiha, A. R., Nurmalina, R., \& Sanim, B. (2018). Kinerja Subsidi Pupuk di Indonesia. Jurnal Aplikasi Bisnis Dan Manajemen, 4(2), 271. https://doi.org/10.17358/jabm.4.2.271 